\title{
Detection of Borrelia burgdorferi by polymerase chain reaction in synovial membrane, but not in synovial fluid from patients with persisting Lyme arthritis after antibiotic therapy
}

Susanne Priem, Gerd R Burmester, Thomas Kamradt, Karsten Wolbart, Michael G Rittig, Andreas Krause

\begin{abstract}
Objectives-To identify possible sites of bacterial persistence in patients with treatment resistant Lyme arthritis. It was determined whether Borrelia burgdorferi DNA may be detectable by polymerase chain reaction (PCR) in synovial membrane (SM) when PCR results from synovial fluid (SF) had become negative after antibiotic therapy.

Methods-Paired SF and SM specimens and urine samples from four patients with ongoing or recurring Lyme arthritis despite previous antibiotic therapy were investigated. A PCR for the detection of $B$ burgdorferi DNA was carried out using primer sets specific for the osp $A$ gene and a $p 66$ gene of $B$ burgdorferi.

Results-In all four cases, PCR with either primer set was negative in SF and urine, but was positive with at least one primer pair in the $S M$ specimens. In all patients arthritis completely resolved after additional antibiotic treatment.

Conclusions-These data suggest that in patients with treatment resistant Lyme arthritis negative PCR results in SF after antibiotic therapy do not rule out the intraarticular persistence of $B$ burgdorferi DNA. Therefore, in these patients both SF and SM should be analysed for borrelial DNA by PCR as positive results in $\mathrm{SM}$ are strongly suggestive of ongoing infection.

(Ann Rheum Dis 1998;57:118-121)
\end{abstract}

Borrelia burgdorferi, the causative agent of Lyme borreliosis, is difficult to detect microscopically or by culture because of the paucity of spirochetes at lesional sites and the long generation period of the borreliae. Therefore, the diagnosis of Lyme disease is usually made clinically and supported by the results of serological tests. ${ }^{1-3}$

In Lyme arthritis, only about one third of European patients remember having had a tick bite or typical clinical features of early Lyme disease like erythema migrans. ${ }^{4}$ Moreover, Lyme arthritis frequently mimics other rheumatological diseases. Serology is sometimes difficult to interprete especially in chronic cases because many patients show an isolated IgG seropositivity that does not discriminate between a past or present infection. ${ }^{35}$ The diagnostic situation can be even more difficult in patients with ongoing or recurring symptoms after antibiotic therapy. In these patients it may be impossible to definitely attribute clinical symptoms to a persisting infection with B burgdorferi.

The polymerase chain reaction (PCR) has recently been shown to sensitively and specifically detect $B$ burgdorfer $i$ DNA in various clinical specimens including synovial fluid (SF) and synovial membrane (SM). In untreated Lyme arthritis patients, PCR in SF reaches a sensitivity of about $85 \%$ and may even exceed $90 \%$ by analysing SF and urine specimens in parallel. ${ }^{467}$ Although a positive PCR only demonstrates the presence of bacterial DNA and not of live organism, it is quite suggestive of an active infection in patients with arthritic symptoms. Therefore, PCR is increasingly used to support the diagnosis of Lyme arthritis. Its role in monitoring the efficacy of antibiotic therapy, however, has not been evaluated yet. After antibiotic therapy, PCR in SF usually becomes negative, but it is not clear if this always indicates the eradication of the spirochetes. ${ }^{6}$ We therefore investigated paired SF/SM samples from patients with treatment resistant Lyme arthritis by PCR.

\section{Methods}

PATIENTS

Four patients with treatment resistant Lyme arthritis were investigated. After referral to our clinic Lyme borreliosis was diagnosed based on the following criteria: all patients lived in an area that is highly endemic for Lyme disease, all patients had a typical monarthritis or oligoarthritis involving the knees, no clinical or serological evidence for other inflammatory rheumatic diseases including rheumatoid arthritis, reactive arthritis or collagen vascular disease could be found, and all patients had a positive serological test for Lyme arthritis according to the CDC criteria. ${ }^{8}$ Table 1 gives the patients' characteristics.

Patient 1, a 50 year old male patient had first been seen by an orthopaedic specialist because of an acute onset arthritis of the left knee. Serological tests had revealed a high IgG antibody titre against $B$ burgdorferi and the diagnosis of Lyme arthritis was made. Doxycycline, $200 \mathrm{mg} /$ day, and diclofenac were prescribed and an intraarticular injection of dexamethasone had been performed. Arthritis persisted with rapidly recurring joint effusions and the 
Table 1 Clinical, demographic, and serological characteristics of the patients studied

\begin{tabular}{|c|c|c|c|c|c|c|}
\hline Patient & $\operatorname{Age}(y) / \operatorname{sex}$ & $\begin{array}{l}\text { Duration of } \\
\text { arthritis } \\
\text { (months) }\end{array}$ & ELISA & Immunoblot $(k D a)$ & Previous antibiotic treatment ${ }^{*}$ & $\begin{array}{l}\text { Previous } \\
\text { corticoid } \\
\text { treatment }\end{array}$ \\
\hline 1 & $50 /$ male & 3 & $\begin{array}{l}\text { IgM neg } \\
\text { IgG pos }\end{array}$ & $\begin{array}{l}\text { IgM: ND† } \\
\text { IgG: } 93,60,41,39,31,29,21\end{array}$ & $\begin{array}{l}\text { ceftriaxone, } 2 \mathrm{~g} \text { for } 28 \text { days } \\
\text { doxycycline, } 200 \mathrm{mg} \text { for } 30 \text { days }\end{array}$ & intraarticular \\
\hline 2 & $51 /$ female & 2 & $\begin{array}{l}\text { IgM neg } \\
\text { IgG pos }\end{array}$ & $\begin{array}{l}\text { IgM: ND } \\
\text { IgG: } 93,72,66,62,60,49,41,39,34,31,25,21\end{array}$ & $\begin{array}{l}\text { ceftriaxone, } 2 \mathrm{~g} \text { for } 21 \text { days } \\
\text { doxycycline, } 200 \mathrm{mg} \text { for } 35 \text { days }\end{array}$ & none \\
\hline 3 & $28 /$ female & 9 & $\operatorname{IgM}$ pos IgG pos & $\begin{array}{l}\text { IgM: } 66,41,39,31,25 \\
\text { IgG: } 93.72,66,62,60,48,41,39,37,34,30,29,25 \text {, } \\
21,18\end{array}$ & $\begin{array}{l}\text { ceftriaxone, } 2 \mathrm{~g} \text { for } 14 \text { days } \\
\text { doxycycline, } 200 \mathrm{mg} \text { for } 30 \text { days }\end{array}$ & intraarticular \\
\hline 4 & 43/female & 7 & $\begin{array}{l}\text { IgM neg } \\
\text { IgG pos }\end{array}$ & $\begin{array}{l}\text { IgM: ND } \\
\text { IgG: } 93,72,66,62,60,48,41,39,37,30,29,28,21\end{array}$ & $\begin{array}{l}\text { ceftriaxone, } 2 \mathrm{~g} \text { for } 14 \text { days } \\
\text { doxycycline, } 200 \mathrm{mg} \text { for } 30 \text { days }\end{array}$ & systemic \\
\hline
\end{tabular}

patient was referred to our clinic. Here the patient presented with a moderate left gonarthritis and pronounced synovial proliferation. Serological examination for Lyme arthritis was positive for IgG antibodies in both ELISA and immunoblot. B burgdorferi DNA was detected in SF by PCR. The patient was treated with ceftriaxone, $2 \mathrm{~g}$ daily for two weeks. The arthritis improved significantly, but then recurred after about six weeks. The patient was treated with ceftriaxone again. Although PCR in synovial fluid became negative, gonarthritis persisted. A popliteal cyst developed and a bursitis of the left elbow occurred. An arthroscopic synovectomy of the left knee and a bursectomy were performed.

The second patient, a 51 year old woman, presented to our outpatient clinic with a two month history of an acute onset bilateral gonarthritis. The patient remembered having had a tick bite and an erythema migrans-like lesion at the right thigh eight years ago. Clinical and ultrasound examinations revealed an active arthritis of the left knee with synovial thickening, a pronounced synovial effusion, and a popliteal cyst. The right knee was only slightly swollen with a pasty thickening of the joint capsule. IgG antibodies against $B$ burgdorferi were detectable by ELISA and immunoblot, and $B$ burgdorferi PCR in SF was positive. The patient was treated with doxycycline 200 $\mathrm{mg} /$ day for four weeks without any effect. Ceftriaxone, $2 \mathrm{~g}$ /day, was given for three weeks with only moderate success. Two months after the antibiotic treatment had been completed the gonarthritis persisted. An arthrocentesis of the left knee with aspiration synovial biopsy was performed.

In patient 3, a 28 year old female patient, a subtotal arthroscopic synovectomy of the right knee had been performed elsewhere because of a gonarthritis with pronounced synovial proliferation that had persisted for nine months. Upon subsequent diagnostic procedures, a positive Lyme serology was observed. Lyme arthritis was diagnosed and treated with ceftriaxone. Treatment had to be discontinued at day 11 because of an allergic rash. Gonarthritis persisted and the patient was seen by a rheumatologist. PCR for $B$ burgdorferi DNA was positive in SF, and doxycycline, 200 $\mathrm{mg}$ /day, was given for 30 days. In addition, corticosteroids were injected intraarticularly. However, only a temporary improvement of the arthritis was seen and the patient was referred to our clinic. Here, the patient presented with a severe arthritis of the right knee joint with a synovial effusion and a popliteal cyst. Lyme serology was positive for both IgG and IgM antibodies in ELISA and immunoblot. Arthroscopy was performed again showing a pronounced proliferation of the newly formed synovial membrane. SF samples and SM biopsy samples were obtained and subjected to PCR.

A 43 year old woman, patient 4 , presented in our outpatient clinic complaining of a bilateral gonarthritis of seven months duration. ELISA and immunoblot showed a high IgG antibody titre against $B$ burgdorferi with several specific bands, and the $B$ burgdorferi $\mathrm{PCR}$ in urine and $\mathrm{SF}$ gave positive results. The patient was treated with ceftriaxone, $2 \mathrm{~g}$ daily for two weeks without any improvement. A few weeks later the patient was seen in another hospital with an acute polyarthritis involving both wrists and several metacarpophalangeal joints and a deterioration of the right gonarthritis. Treatment with doxycycline, $200 \mathrm{mg}$ daily for 30 days, and prednisolone 10-20 mg per day was started. Again, there was no sufficient response and the patient was referred to our clinic. A closed needle arthrocentesis with synovial biopsy of the right knee was performed.

PCR

PCR was performed as described previously. ${ }^{4}$ In brief, $1-10 \mathrm{ml}$ of $\mathrm{SF}$ or urine were centrifuged at $350 \mathrm{~g}$ for 20 minutes at $10^{\circ} \mathrm{C}$. The pellet obtained was washed with $0.9 \%$ saline, cells were pelleted again, and DNA was extracted from the pellet by alkaline lysis. SM samples were disrupted mechanically, followed by a freeze and thaw procedure. The pieces obtained were subjected to alkaline lysis. Boiled B burgdorferi sensu stricto (strain LW2) ${ }^{9}$ were used as positive control (external amplification control). Negative controls with water and SF were also run in every determination.

Nested PCR was performed with two primer sets (TIB Molbiol, Berlin, Germany) targeting $B$ burgdorferi specific gene sequences. One primer set (osp $A$ primer) was specific for a portion of the plasmid located $\operatorname{ssp} A$ gene ( $5^{\prime}$ outer primer GGG AAT AGG TCT AAT ATT AGC C; 3' outer primer CAC TAA TTG TTA AAG TGG AAG $\mathrm{T}$; 5' nested primer GCA AAA TGT TAG CAG CCT TGA T; 3' nested primer CTG TGT ATT CAA GTC TGG C; length of amplicons: 665 and 392 bp; EMBL accession number X66065). ${ }^{10}$ The second primer set ( $p 66$ primer) targeted a sequence of 
a chromosomal gene encoding a $66 \mathrm{kDa}$ protein (5' outer primer CGA AGA TAC TAA ATC TGT; 3' outer primer GAT CAA ATA TTT CAG CTT; 5' nested primer TGC AGA AAC ACC TTT TGA AT; 3' nested primer AAT CAG TTC CCA TTT GCA; length of amplicons 371 and $236 \mathrm{bp}$; EMBL accession number M58429). ${ }^{11} 12$

As an internal amplification control, a primer pair specific for the pyruvate dehydrogenase gene (PDH primer) was used (5' GGT ATG GAT GAG GAG CTG GA; 3' CAG CCC TCG ACT AAC CTT GT; length of the amplicon 185 bp; EMBL accession number J03576). ${ }^{13}$

The PCR reaction mixture (total volume 25 $\mu 1$ ) contained $2.5 \mu \mathrm{l}$ of the isolated DNA, $2.5 \mu \mathrm{l}$ 10-fold PCR buffer (Perkin Elmer Cetus, Norwalk, CT; final concentration $10 \mathrm{mM}$ TRIS$\mathrm{HCl}, 50 \mathrm{mM} \mathrm{KCl}, 1.5 \mathrm{mM} \mathrm{MgCl}, 0.001 \%$ (w/v) gelatine), $0.3 \mu \mathrm{M}$ of each primer, $200 \mu \mathrm{M}$ of each nucleotide (Boehringer Mannheim, Mannheim, Germany), and $0.8 \mathrm{U}$ of Taq polymerase (Ampli Taq, Perkin Elmer Cetus). The outer PCR was carried out with a total of 40 cycles: DNA was denatured at $94^{\circ} \mathrm{C}$ for one minute, primers annealed at $42^{\circ} \mathrm{C}$ for one minute, and extended at $72^{\circ} \mathrm{C}$ for one minute. Nested PCR was performed with $2.5 \mu$ of the outer amplicons as template. Twenty five cycles were carried out with the temperature profile described above. Amplicons were visualised on a 3\% agarose gel stained with ethidium bromide and photodocumented using a gel documentation system (Appligene imager, Appligene Oncor, Heidelberg, Germany).

\section{Results}

Patients were evaluated 8 to 10 weeks after antibiotic treatment had been completed. At the time of investigation, all four patients were still seropositive and had an active arthritis despite previous antibiotic therapies (table 1). Urine samples were collected and within one week SF and SM specimens were obtained in parallel by arthrocentesis with needle biopsy, arthroscopic biopsy or arthroscopic synovectomy, respectively. In none of the SF and urine samples could $B$ burgdorferi DNA be detected by PCR. In contrast, in SM samples $B$ burgdorferi PCR was positive (fig 1). SM samples of patient 1 and 2 showed positive PCR results with the $\operatorname{ssp} A$ primer while the SM specimen of patient 3 was PCR positive with the $p 66$ primer only. SM samples from patient 4 were PCR positive with both primer sets (table 2). Additionally, in the material obtained by bursectomy from patient $1 B$ burgdorferi could be detected by PCR with the $\operatorname{sp} p A$ primer.
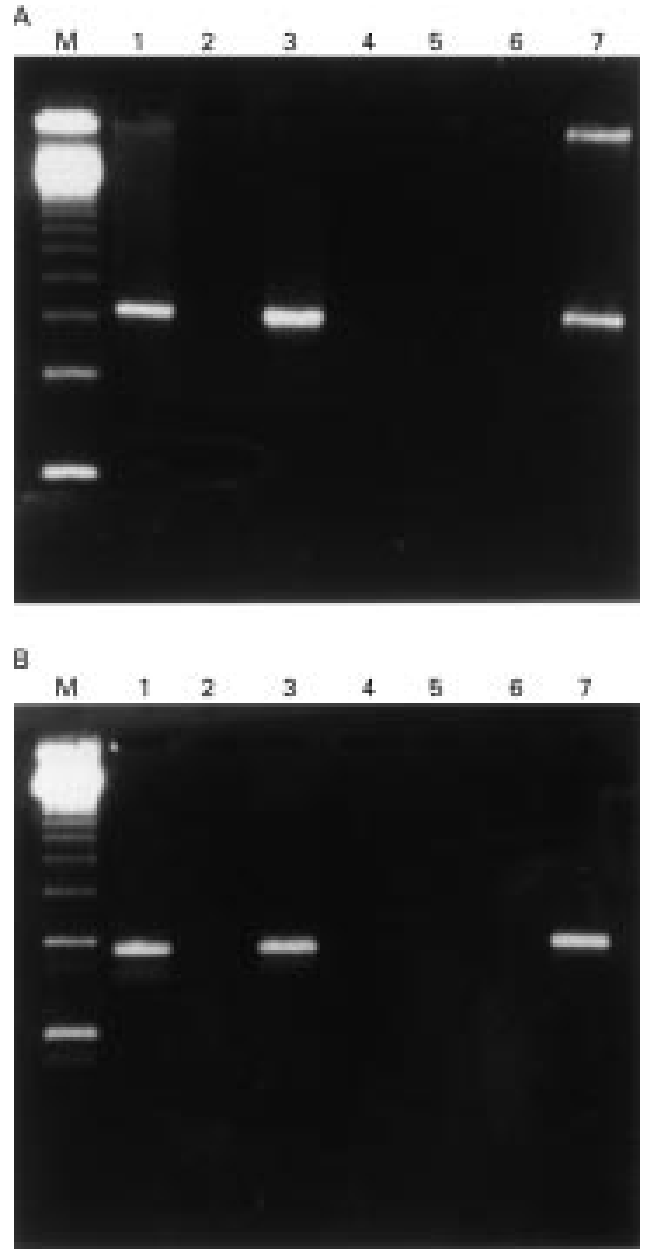

Figure 1 Detection of $(A)$ osp $A$ and $(B)$ p66 gene sequences of $B$ burgdorferi by PCR in SF and SM from patient 4. Nested PCR products were visualised on a $3 \%$ agarose gel stained with ethidium bromide. At presentation in our clinic, PCR was positive in SF (lane 3). After antibiotic therapy, PCR became negative in SF (lane 5) but was positive in SM (lane 7). Lane M: molecular weight markers, lane 1: positive control (B burgdorferi sensu stricto, strain LW2), lanes 3, 4, 6: negative control (water lane).

Because of the persisting arthritis and these PCR findings, all patients were treated again with antibiotics. Patients 1,2 , and 4 received cefotaxime, $2 \mathrm{~g}$ three times per day, for three weeks, followed by a six week course with oral doxycycline or minocycline $(200 \mathrm{mg} /$ daily $)$, respectively. Patient 3 was treated with imipenem, $1.0 \mathrm{~g}$ three times per day, for two weeks and, subsequently, with $200 \mathrm{mg}$ doxycycline per day for six weeks. In all four patients arthritis completely subsided within four to six months and did not recur after a median observation period of 18 months.

Table $2 \quad P C R$ results in SF, urine, and SM before and after antibiotic treatment

\begin{tabular}{|c|c|c|c|c|c|c|c|c|}
\hline \multirow[b]{3}{*}{ Patient } & \multirow{2}{*}{\multicolumn{2}{|c|}{$\begin{array}{l}\text { PCR in synovial before antibiotic } \\
\text { treatment }\end{array}$}} & \multicolumn{6}{|c|}{ PCR after antibiotic treatment } \\
\hline & & & \multicolumn{2}{|l|}{ PCR in urine } & \multicolumn{2}{|l|}{$P C R$ in $S F$} & \multicolumn{2}{|l|}{ PCR in $S M$} \\
\hline & osp $A$ primer & p66 primer & osp $A$ primer & p66 primer & osp $A$ primer & p66 primer & ospA primer & p 66 primer \\
\hline 1 & positive & negative & negative & negative & negative & negative & positive & negative \\
\hline 2 & positive & negative & negative & negative & negative & negative & positive & negative \\
\hline 3 & negative & positive & negative & negative & negative & negative & negative & positive \\
\hline 4 & positive & positive & negative & negative & negative & negative & positive & positive \\
\hline
\end{tabular}




\section{Discussion}

Previous studies have demonstrated that PCR is a valuable tool in supporting the diagnosis of Lyme borreliosis. ${ }^{467}$ However, only little is known about the value of PCR analysis in monitoring the disease course and in evaluating the efficacy of treatment. Further treatment decisions are easily made in patients with ongoing arthritis and positive PCR or patients with good clinical reponse to antibiotic therapy and negative PCR results. The situation is much more complicated, however, if PCR in $\mathrm{SF}$ has become negative after antibiotic treatment despite persistence of arthritis. ${ }^{6}$ While on the one hand in these patients arthritis may be mediated by infection induced immunopathology, ${ }^{14}$ the lack of borrelial DNA in SF on the other hand does not necessarily rule out the intraarticular persistence of spirochetes, for example, in SM.

In this study we describe four patients with gonarthritides who were PCR positive for $B$ burgdorferi DNA in $\mathrm{SF}$ at presentation in our clinic. After repeated oral and parenteral antibiotic therapy PCR became negative in both $\mathrm{SF}$ and urine although arthritides were resistant to treatment in these patients. However, in all four patients borrelial DNA could readily be detected in SM specimens indicating persistence of bacterial DNA. As in all patients arthritis resolved after additional antibiotic treatment PCR results were suggestive of microbial persistence.

These results extend those of a recent study by Jaulhac et $a l^{15}$ who were the first ones to describe the detection of $B$ burgdorferi DNA in SM samples by PCR. Among the 12 patients investigated in that study, three had been treated with antibiotics previously. In two of these patients PCR was positive in SM only, but negative in SF. However, while the sensitivity of PCR was $83 \%$ in SM, sensitivity of the PCR in SF was only $50 \%$ even in untreated patients making the protocol described more suitable for SM analysis. In our study we used an optimised PCR protocol that detects $B$ burgdorferi DNA in over $80 \%$ of patients with Lyme arthritis by analysing SF alone and in over $90 \%$ by analysing paired SF urine samples. ${ }^{4}$ Despite this high sensitivity, PCR was negative in both SF and urine samples in our patients who had been treated with antibiotics.

Although positive PCR results do not prove infection by living bacteria, persistence of DNA raises the possibility of persisting active infection. The mechanisms by which $B$ burgdorferi may have escaped the antibiotic episode remains to be elucidated. It has been shown previously by us and others that $B$ burgdorferi evades into specific sites that are only incompletely accessible to antibiotics and the immune system. ${ }^{9}$ Moreover, evidence emerged from in vitro studies that the spirochetes may persist within synovial fibroblasts. ${ }^{16}$ This prompted us to treat our patients with parenteral cephalosporins to achieve high tissue concentrations, followed by treatment with doxycycline or minocycline that acts on intracellular microorganisms. In all four patients this regimen was able to cure the arthritis. Controlled studies will be necessary to further evaluate this therapeutic approach in otherwise treatment resistant infections.

Taken together, this study shows that in patients with ongoing or recurring Lyme arthritis after antibiotic therapy a negative $B$ burgdorferi PCR in SF or urine does not necessarily exclude a persisting infection. In these patients, SM biopsy specimens should be obtained for PCR analysis, which is much more sensitive than SF-PCR to detect intraarticular persistence of the bacterial DNA. This is important because PCR positive patients are likely to suffer from ongoing infection and therefore may benefit from additional antibiotic therapy.

This study was supported by the Bundesministerium für Bildung, Wissenschaft, Forschung und Technologie, grants 01 KI 9104 and 01 KI 9503. The Deutsches Rheumaforschungszentrum is supported by the Senatsverwaltung für Wissenschaft und Forschung Berlin. The authors thank Diana Lahn for skilful technical assistance. The data were presented in part at the VII International Conference on Lyme Borreliosis, San Francisco, California, USA, June 1996 (abstract D661).

1 Kalish R. Lyme disease. Rheum Dis Clin North Am 1993;19:399-426.

2 Steere AC. Lyme disease. N Engl J Med 1989;321:586-96.

Tilton RC. Laboratory aids for the diagnosis of Borrelia burgdorferi infection. Journal of Spirochetal and Tick-Borne Diseases 1994;1:18-23.

4 Priem S, Rittig MG, Kamradt T, Burmester GR, Krause A. An optimized PCR leads to rapid and highly sensitive detection of Borrelia burgdorferi in patients with Lyme borreliosis. J Clin Microbiol 1997;35:685-90.

5 Engstrom SM, Shoop E, Johnson RC. Immunoblot interpretation criteria for serodiagnosis of early Lyme disease. J Clin Microbiol 1995;33:419-27.

6 Nocton JJ, Dressler F, Rutledge BJ, Rys PN, Persing DH, Steere AC. Detection of Borrelia burgdorferi DNA by polymerase chain reaction in synovial fluid from patients polymerase chain reaction in synovial fluid from patien

7 Liebling MR, Nishio MJ, Rodriguez A, Sigal LH, Jin T, Louie JS. The polymerase chain reaction for the detection
Liebling MR, Nishio MJ, Rodriguez A, Sigal LH, Jin T, of Borrelia burgdorferi in human body fluids. Arthritis Rheum 1993;36:665-75.

8 CDC: Recommendations for test performance and interpretation from the Second National Conference on Serologic Diagnosis of Lyme Disease. MMWR Morb Mortal Wkly Rep 1995;44:590-1.

9 Haeupl T, Hahn G, Rittig M, Krause A, Schoerner C, Schonherr U, et al. Persistence of Borrelia burgdorferi in igamentous tissue from a patient with chronic Lyme borreliosis. Arthritis Rheum 1993;36:1621-6.

10 Moter SE, Hofmann H, Wallich R, Simon MM, Kramer MD. Detection of Borrelia burgdorferi sensu lato in lesional skin of patients with erythema migrans and acrodermatitis skin of patients with erythema migrans and acrodermatitis
chronica atrophicans by ospA-specific PCR. J Clin Microbiol 1994;32:2980-8.

11 Rosa PA, Schwan TG. A specific and sensitive assay for the Lyme disease spirochete Borrelia burgdorferi using the polymerase chain reaction. J Infect Dis 1989;160:1018-29.

12 Probert WS, Allsup KM, LeFebvre RB. Identification and characterization of a surface-exposed, 66-kilodalton protein from Borrelia burgdorferi. Infect Immun 1995;63: 1933-9.

13 Rolfs A, Schuller I, Finckh U, Weber-Rolfs I. PCR: clinical diagnostics and research. Berlin: Springer Laboratory, Springer Verlag, 1992:79-80.

14 Kuiper H, van Dam AP, Spanjaard L, de Jongh BM, Widjojokusumo A, Ramselaar TC, et al. Isolation of Borrelia burgdorferi from biopsy specimens taken from healthylooking skin of patients with Lyme borreliosis. J Clin Microbiol 1994;32:715-20.

15 Jaulhac B, Chary-Valckenaere I, Sibilla J, Javier RM, Piémont Y, Kuntz JL, et al. Detection of Borrelia burgdorferi by DNA amplification in synovial tissue samples from by DNA amplification in synovial tissue samples from patients

16 Girschick HJ, Huppertz HI, Rüssmann H, Krenn V, Karch $\mathrm{H}$. Intracellular persistence of Borrelia burgdorferi in human synovial cells. Rheumatol Int 1996;16:125-32. 